\title{
Source material for quince varieties selection with high commercial and consumer qualities of fruits in the Krymsk EBS, VIR Branch gene pool
}

\author{
Irina Chepinoga*, and Anna Tikhonova \\ Krymsk Experiment Breeding Station of VIR, N.I. Vavilov All-Russian Institute of Plant Genetic \\ Resources, Krymsk, Krasnodar Region, Russia
}

\begin{abstract}
The article presents the evaluation results of varieties, samples, and breeding elites of quince from the gene pool of VIR named after N.I. Vavilov preserved at the Krymsk EBS, VIR Branch. The article presents generalized material based on the study of technical parameters, biochemical composition of quince fruits and products of technological processing (canned food: juice, compote, jam). Differences between varieties by fruit weight and in terms of biochemical indicators content were established: soluble dry substances, sugars, sum of organic acids, ascorbic acid. In the conditions of southern Russia, quince fruits contain relatively higher levels of soluble dry substances (1.2-1.8 times) and ascorbic acid (1.5-2.0 times) compared to apples. According to the research results, selectionally valuable sources of high commercial fruit quality were distinguished, including attractiveness of appearance, taste and density of pulp, organoleptic, biochemical parameters of fresh fruits and evaluation of conversion products: Vernaya, Zvezdnaya, Granitnaya, elite 21-4-51. Varieties - sources of high content of soluble dry substances (23.30-24.58\%), organic acids (1.45-1.76\%), sugars (13.30-14.90\%), ascorbic acid (37.01-42.24 mg/100 g) were identified. For amateur gardening, quince species forms Kaunchi 8, Kaunchi 9, Jardem are proposed as they are juicy, soft, with good biochemical indicators.
\end{abstract}

\section{Introduction}

Being valuable in nutritional properties, such seed crop as quince currently occupies a very small proportion in the garden agrocenosis. However, its fruits can increase the variety of fresh products almost all year round, as well as canned. In the south of Russia, the natural and climatic conditions are quite favorable for increasing the specific weight of this crop. Quince is a monotype genus consisting of the single species Cidonia oblonga Mill. quince tree. All cultivated quince varieties are representatives of this species. Quince is an early-maturing, high-yielding fruit crop with a restrained type of growth and a compact crown, which allows to cultivate its varieties with the use of intensive technologies. By economic efficiency, this is one of highly profitable seed crops [1]. Quince fruits are valued

\footnotetext{
* Corresponding author: kross67@mail.ru
} 
for their high taste and dietary qualities. They contain a large amount of mineral (iron, copper, etc.) and biologically active substances: organic acids, pectins, fructose, glucose, complex of vitamins - A, $\mathrm{B}_{1}, \mathrm{~B}_{2}, \mathrm{C}, \mathrm{P}[2,3]$. Pectin substances improve organoleptic properties of fruits and conversion products, preserve aromatic substances. Quince is very promising for canned food and confectionery industry. High-quality juices, compotes, jams, marmalade, confiture, candied fruits, and other products are produced from quince fruits, which are highly appreciated for its attractive appearance, excellent taste and bright pronounced specific aroma [4]. Since pectin substances have the ability to complex formation with heavy and radioactive metals, thus forming insoluble complexes with various toxins accumulating in the human body, juice with pulp and other conversion products are functional foods that help to cleanse the body and improve human immunity [5].

However, the quince varieties' lack of universal purpose with a good combination of high taste and canned qualities of the fruit, as well as the food priorities of the population deter the use of this crop in canned food industry. Increasing the production of canned food from quince fruits is possible only based on new varieties creation, their rapid involvement in gardening rotation and processing industry.

Solving the problems of quince assortment improvement requires the use of new donors and sources in breeding, which is possible through a comprehensive potential assessment of both modern varieties and representatives of public breeding varieties. Krymsk EBS, VIR Branch (Krasnodar Region) is studying the quince gene pool represented by more than 160 varieties of various ecological, geographical and genetic origin and elites obtained by the intervariety cross-breeding method [6]. The allocation of new donors and sources, critical selectionally significant traits will allow to improve the effectiveness of targeted breeding programs.

\section{Purpose of research}

To assess varieties and samples of quince from the gene pool of N.I. Vavilov All-Russian Institute of Plant Genetic Resources supported at the Krymsk EBS, VIR Branch on a set of technical indicators, determine the organoleptic fruit characteristics, study their biochemical composition and suitability for technological processing. To identify new valuable genotypes for introduction into production, as well as sources of high commercial fruits' characteristics for involvement in targeted breeding programs to improve the fruit quality.

\section{Materials and methods}

The research was carried out at the Krymsk EBS structural subdivision of N.I. Vavilov AllRussian Institute of Plant Genetic Resources located in the Western sub-zone of the Foothill Zone of Krasnodar Region. Objects of research - 50 varieties of domestic and foreign origin and 8 elite quince forms of the Krymsk EBS, VIR Branch selection. Genotypes grafted on clone rootstock VA 29 grow in the dryland garden, placement scheme - $4.0 \times 1.5$ $\mathrm{m}$, planting year - 2010. The soils are gray forest.

Quince variety samples were evaluated by consumer qualities of fresh fruits: weight and appearance of the fruit, pulp density, taste qualities according to generally accepted methods [7-8], as well as biochemical composition according to GOST 28562, GOST 25555.0, GOST R 51240. Conversion products (juice, compote, jam) were made according to GOST 32105-2013, R 54680-2011 [9]. Juice with pulp was evaluated by color and taste; compote and jam - by appearance, color, pulp consistency, taste; the overall assessment for 
the variety was determined by all traits. Experimental data was processed by dispersion analysis using MS Excel computer program with AgCStat add-in [10].

\section{Results and discussion}

In the southern regions of the Russian Federation, quince fruits form the best commercial and full-fledged food qualities. The main parameters characterizing the economic value of the variety are the commercial and consumer qualities of fruits, among which the appearance, weight, pulp density and taste occupy the first place. (Table 1). They depend on variety-specific features, genetic origin. To determine the differences' validity in the fruit weight between the studied varieties and quince elites, a one-factor dispersion analysis was performed, as a result of which significant differences of options were revealed for the level accepted in studies $(\mathrm{P}=0.95)$.

Table 1. Technical indicators of fresh quince fruits of promising varieties and elites Krymsk EBS, VIR Branch, rootstock BA 29, 2010 planting according to the scheme $4.0 \times 1.5 \mathrm{~m}$ )

\begin{tabular}{|l|l|l|c|c|c|}
\hline \multicolumn{1}{|c|}{ Variety, elite } & \multicolumn{1}{|c|}{ Origin } & Fruit weight, g & $\begin{array}{c}\text { Appearance, } \\
\text { score }\end{array}$ & $\begin{array}{c}\text { Taste, } \\
\text { score }\end{array}$ & $\begin{array}{c}\text { Pulp } \\
\text { density, } \\
\text { score }\end{array}$ \\
\hline Kubanskaya, St & Krasnodar Region & $305.9 \pm 65.0$ & 4.4 & 4.5 & 5 \\
\hline Adagumskaya & Krasnodar Region & $319.9 \pm 48.8$ & 4.5 & 4.6 & 4 \\
\hline Vernaya & Krasnodar Region & $293.3 \pm 16.0$ & 4.7 & 4.7 & 4 \\
\hline Zolotistaya & Krasnodar Region & $241.0 \pm 15.0$ & & & 4 \\
\hline Granitnaya & Krasnodar Region & $353.3 \pm 19.8$ & 4.9 & 4.8 & 4 \\
\hline Novogodnyaya & Krasnodar Region & $307.4 \pm 35.4$ & 4.7 & 4.8 & 4 \\
\hline Zvezdnaya & Krasnodar Region & $334.4 \pm 23.2$ & 4.7 & 4.8 & 4 \\
\hline Krasnoslobodskaya & Volgograd Region & $286.1 \pm 29.4$ & 4.5 & 4.6 & 4 \\
\hline Muskatnaya & South of Russia & $266.0 \pm 24.4$ & 4.5 & 4.7 & 3 \\
\hline Obil'naya & Republic of & $328.1 \pm 19.4$ & & & 3 \\
\hline Ispolinskaya & Ehechnya & $360.7 \pm 20.2$ & 4.6 & 4.6 & 4 \\
\hline Dzhardem & Armenia & $252.0 \pm 35.4$ & 4.6 & 4.7 & 1 \\
\hline Kaunchi No.8 & Uzbekistan & $267.5 \pm 29.2$ & 4.7 & 4.8 & 2 \\
\hline Kaunchi No.9 & Uzbekistan & $332.3 \pm 34.6$ & 4.7 & 4.8 & 1 \\
\hline Elite No.8-21-2 & Krasnodar Region & $348.0 \pm 10.4$ & 4.8 & 4.7 & 4 \\
\hline Elite No.24-4-51 & Krasnodar Region & $340.5 \pm 24.6$ & 4.9 & 4.8 & 4 \\
\hline Elite No.8-24-1 & Krasnodar Region & $303.6 \pm 23.8$ & 4.7 & 4.7 & 3 \\
\hline & & $\mathrm{F}_{\mathrm{A}} 5.16>\mathrm{F}_{095}$ & & & \\
\hline & & LCD: 44.51 & & & \\
\hline
\end{tabular}

Note: pulp density score: 1-very soft, 2-soft, 3-medium dense, 4-dense, 5-very dense

For the processing industry, preferred quince fruits are of round shape with an even surface, rich yellow color, sweet and sour taste, unidimensional, medium or large size, with a dense pulp. As a result of many research years, varieties Granitnaya, Zvezdnaya, Vernaya, Novogodnyaya, elite 24-4-51, 8-21-2 were distinguished as sources of a trait complex of high-quality fruits for the canned food industry.

For quince varieties selection for dessert purposes, samples introduced from the natural populations of Central Asia and Southern Transcaucasia were selected from the collection: Kaunchi No.8, No.9, Zhardem. Along with high taste qualities, the size of the fruits from medium to large, they are characterized by a comparatively juicy pulp and soft fruitiness.

The food and nutritional advantages of fruits are determined by their biochemical composition. Studies have shown that the content of dry substances, sugars, organic and ascorbic acids of the studied quince varieties varies significantly depending on the biological characteristics of a variety. On average, quince fruits contain dry substances from 1.2 to 1.8 times more than in apple fruit [11]. This property is especially valuable for 
the processing industry in the manufacture of juices with pulp, puree and other canned food. By the time of technical maturity, quince fruits contain from 18 to $25 \%$ of soluble dry substances (SDS). Varieties and elites with denser fruit consistency are characterized by high content of SDS (23.30-24.58) - Granitnaya, Zvezdnaya, Vernaya, elite 24-4-51. In the collection samples Zhardem and Kaunchi No.8, the SDS content varies from 18.69 to $19.04 \%$ and their fruits are juicier and softer in comparison with other varieties (Figure 1).
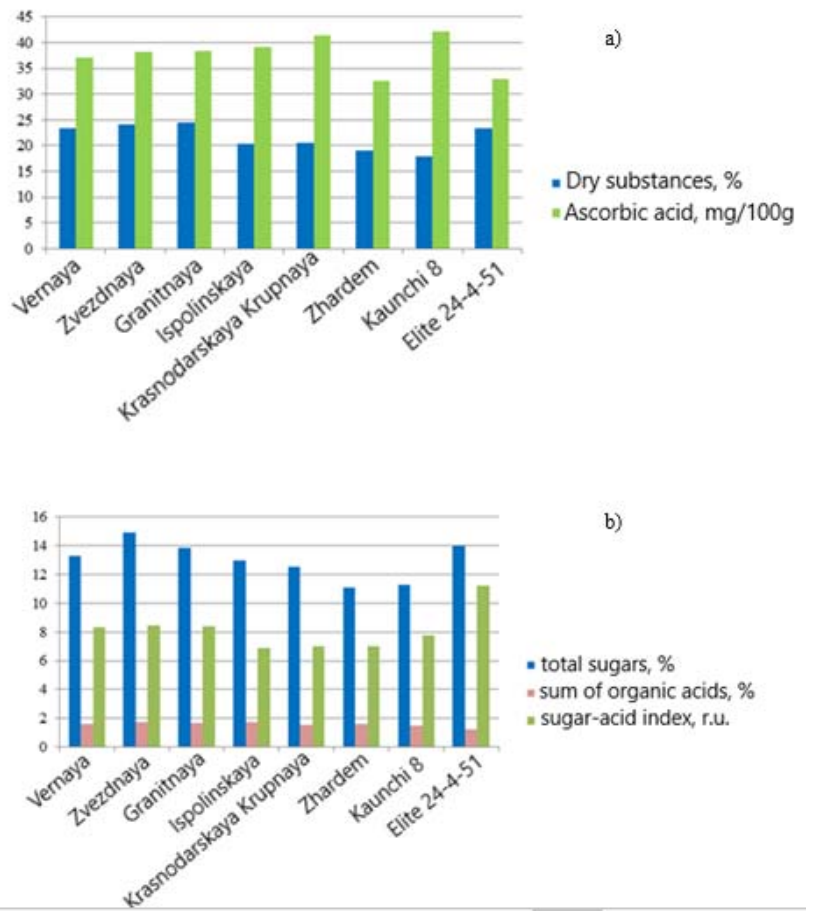

Fig. 1. Biochemical composition of quince fruits in conditions of southwestern zone of Krasnodar Region (Krymsk EBS, VIR Branch)

(a) Dry soluble substances, $\%$; ascorbic acid, $\mathrm{mg} / 100 \mathrm{~g}$;

b) total sugars, $\%$; sum of organic acids, $\%$; sugar-acid index, r.u.

The ascorbic acid content in fruits is one of the most important biological features for horticultural crops. Quince fruit has 1.5-2 times higher vitamin C content than apple trees. Out of promising varieties and elites, varieties with the highest content of ascorbic acid in fruits were determined: Zvezdnaya (38.15 mg/100 g), Granitnaya (38.45 mg/100 g), Vernaya (37.01 mg/100 g), Ispolinskaya (39.07 mg) /100 g), Krasnodarskaya Krupnaya (41.36 mg/100 g), Kaunchi 8 (42.24 mg/100 g).

By the sum of total sugars, the best indicators were shown by varieties: Vernaya (13.30\%), Granitnaya (13.85\%), Zvezdnaya (14.90\%), Ispolinskaya (13.00\%), elite $24-4-51$ $(14.00 \%)$.

The organic acids content in quince fruits in the conditions of the South-West Caucasus varies from 0.60 to $1.76 \%$. The largest indicators of the sum of organic acids in the quince varieties fruits: Vernaya (1.59\%), Zvezdnaya (1.76\%), Granitnaya (1.65\%), Ispolinskaya (1.75\%), Krasnodarskaya Krupnoplodnaya (1.55\%), Zhardem (1.58\%), Kaunchi 8 (1.45\%).

The harmonious taste of fruits is determined by the ratio of sugar and organic acids content. High indicator of the sugar-acid index (over 8 relative units - r.u.) in varieties: Vernaya (8.36 r.u.), Zvezdnaya (8.46 r.u.), Granitnaya (8.39 r.u.), elite 24-4-51 (11.2 r.u.). 
According to the biochemical indices complex of quince fruits, the following varieties are identified as high content sources of dry substances, vitamin C, sugars, optimal ratio of total sugars and the sum of organic acids of the: Zvezdnaya, Vernaya, Granitnaya, Ispolinskaya, elite 24-4-51; on the basis of the "least amount of dry substances" index at optimal values of other biochemical indices — soft-fruit species forms Zhardem and Kaunchi 8.

High content of soluble dry substances in quince fruit pulp, as well as harmonious combination of sugars and organic acids allows to make high-value conversion products from it: juice with pulp, compote, jam. As a result of tasting sessions, the canned products of all researched quince varieties received high scores (Table 2). According to the assessment results of juice products (2017-2019), the best varieties were allocated: Granitnaya (4.83 points), Novogodnyaya (4.72 points). Canned "compote" products had higher ratings in varieties: Granitnaya (4.77 points), Novogodnyaya (4.68 points), Izobil'naya (4.64 points). The taste of jam of all tested quince varieties was very good. Especially high scores for all tasting parameters of jam were obtained in varieties: Izobil'naya, Granitnaya, Novogodnyaya (4.77 points), Blagodatnaya (4.73 points).

Table 2. Tasting evaluation of conversion products of quince fruit's promising varieties and elites (Krymsk EBS, VIR Branch)

\begin{tabular}{|l|c|c|c|}
\hline \multirow{2}{*}{ Variety } & \multicolumn{3}{|c|}{ Overall score, points } \\
\cline { 2 - 4 } & Juice & Compote & Jam \\
\cline { 2 - 4 } & & $4.56 \pm 0.17$ & $4.68 \pm 0.17$ \\
\hline Zoloto Skifov, St & $4.62 \pm 0.22$ & $4.64 \pm 0.10$ & $4.77 \pm 0.13$ \\
\hline Izobil'naya & $4.55 \pm 0.44$ & $4.61 \pm 0.17$ & $4.66 \pm 0.15$ \\
\hline Zolotistaya & $4.42 \pm 0.21$ & $4.51 \pm 0.21$ & $4.59 \pm 0.13$ \\
\hline Kubanochka & $4.40 \pm 0.21$ & $4.43 \pm 0.05$ & $4.65 \pm 0.15$ \\
\hline Myagkoplodnaya & $4.54 \pm 0.36$ & $4.82 \pm 0.17$ & $4.77 \pm 0.10$ \\
Volgogradskaya & $4.83 \pm 0.17$ & $4.55 \pm 0.06$ & $4.61 \pm 0.10$ \\
\hline Granitnaya & $4.41 \pm 0.08$ & $4.57 \pm 0.11$ & $4.73 \pm 0.16$ \\
\hline Adagumskaya & $4.57 \pm 0.13$ & $4.73 \pm 0.18$ & $4.77 \pm 0.10$ \\
\hline Blagodatnaya & $4.72 \pm 0.18$ & $4.53 \pm 0.29$ & $4.64 \pm 0.29$ \\
\hline Novogodnyaya & $4.56 \pm 0.13$ & $\mathrm{~F}_{\mathrm{A}} 1.04<\mathrm{F}_{095}$ & $\mathrm{~F}_{\mathrm{A}} 0.07<\mathrm{F}_{095}$ \\
\hline Muskatnaya & $\mathrm{F}_{\mathrm{A}} 7.32>\mathrm{F}_{095}$ & $\mathrm{~F}_{\mathrm{B}} 2.92>\mathrm{F}_{095}$ & $\mathrm{~F}_{\mathrm{B}} 4.28>\mathrm{F}_{095}$ \\
\hline & $\mathrm{F}_{\mathrm{B}} 5.44>\mathrm{F}_{095}$ & $\mathrm{LCD}: 0.19$ & $\mathrm{LCD} 0.17$ \\
\hline
\end{tabular}

Note: factor $A$ - year; factor $B$ - variety

According to the set of qualitative indicators of conversion products (juice, compote, jam), complex sources of canned qualities were identified: Granitnaya and Novogodnyaya. The most high-quality products are obtained from these varieties.

Given the high-quality indicators of fresh fruits and conversion products, Granitnaya and Novogodnyaya quince varieties are recommended for a wide variety trial on a farm scale in the south of the Russian Federation; they are also passing the State strain testing.

\section{Conclusions}

According to the fruits' content of biologically active substances that characterize the nutritional value, the followng varieties were distinguished as sources: Vernaya, Zvezdnaya, Granitnaya, elite 21-4-51. For amateur gardeners, quince species forms attracted to the gene pool from Central Asia are proposed - Kaunchi 8, Kaunchi 9; and 
from South Transcaucasia - Zhardem, juicy, soft-fruit, with high rates of general sugars, amounts of organic acids and vitamin $\mathrm{C}$.

Based on the study results of the quince gene pool of the Krymsk EBS, VIR Branch, sources of valuable traits have been identified according to the complex of fresh fruits quality indicators - weight, attractive appearance, taste, density of pulp and conversion products - juice, compote, jam, selected varieties: Granitnaya and Novogodnyaya. Their use in breeding programs will allow to create quince varieties with specified qualitative indicators.

Quince with excellent taste of fresh fruits containing healthy organic substances, from which high value conversion products are made, belonging to functional food products with medicinal, preventive properties should take an appropriate place both in the industrial gardens of the south of Russia and in the processing industry.

\section{Acknowledgements}

The work was performed on the VIR Collections of Plant Genetic Resources within the framework of the state task according to the thematic VIR plan on the project No. 06622019-0004 "Collections of vegetatively propagated crops (potatoes, fruit, berry, ornamental, grapes) and their wild relatives VIR — Study and Rational Use"

\section{References}

1. M.A. Azamatov, Bulletin of Orel SAU, 3 (36), 94 (2012)

2. J. Pennington, R. Fisher Journal of Food composition and Analysis, 23, 411 (2010)

3. M. Asensi-Fabado, S. Munne-Bosh Trends in Plant Science, 15(10), 582 (2010)

4. S.N. Edygova, Materials of the VII All-Russian Scient.-pract conf.

5. L.Ya. Rodionova Storage and processing of agricultural raw materials, 3, 25 (1994)

6. I.S. Chepinoga, A.V. Tikhonova, Subtropical and ornamental horticulture, 53, 72 (2015)

7. E.N. Sedov, T.P. Ogoltsova, Program and methodology of variety study of fruit, berry and nut crops, 608 (1999)

8. E.A.Egorov, G.V. Eremin, I.A. Ilyina, The program of the North Caucasus Center for the selection of fruit, berry, floral-ornamental crops and grapes for the period up to 2030, 202 (2013)

9. Conversion products of fruits and vegetables. Methods of analysis, 200 (2002)

10. P.P. Gonchar-Zaykin, V.G. Chertov Rational environmental management and agricultural production in the southern regions of the Russian Federation: Coll. of articles, 559 (2003)

11. E.N. Sedova, Pomology. Pear, 2, 436 (2007) 